\title{
PENGENDAPAN LOGAM TEMBAGA DENGAN METODA ELEKTROLISIS INTERNAL
}

\author{
Abdul Haris, Ani Dwi Riyanti, Gunawan \\ Laboratorium Kimia Analitik Jurusan Kimia \\ F MIPA Universitas Diponegoro, Semarang 50275
}

\begin{abstract}
ABSTRAK
Telah dilakukan penelitian tentang pengaruh waktu elektrolisis, jarak antar elektroda dan penggunaan membran terhadap pengendapan tembaga dengan metoda elektrolisis internal dan aplikasinya pada limbah PCB (Printed Circuit Board). Dari penelitian diketahui bahwa waktu elektrolisis jarak antar elektroda dan penggunaan membran berpengaruh terhadap pengendapan logam tembaga dengan metoda elektrolisis internal. Pengaruh faktor-faktor tersebut adalah waktu berbanding lurus dengan massa tembaga yang mengedap, jarak antar elektroda berbanding terbalik dengan massa tembaga yang mengendap. Metoda elektrolisis internal mampu menurunkan kadar limbah PCB sampai $96,88 \%$.
\end{abstract}

Kata kunci: elektrolisis internal, tembaga

\section{ABSTRACT}

The research has been done to evaluate the effect of electrolysis time, electrode distance, membrane application on copper deposition by internal electrolysis and its application in PCB (Printed Circuit Board). The experimental results showed that electrolysis time, electrode distance and membrane had effect on copper deposition by internal electrolysis method. The electrolysis time is directly proportional to the mass of copper deposited, while electrode distance is indirectly proportional to the mass of copper deposited. The method was to decrease the copper concentration in PCB waste by $96,88 \%$.

Key words: internal electrolysis, copper

\section{PENDAHULUAN}

Salah satu jenis pencemaran lingkungan yang dihadapi sat ini adalah disebabkan oleh logamlogam berat di antaranya adalah logam berat tembaga yang terdapat pada limbah cair. Sumber-sumber penyumbang pencemaran logam berat tembaga dapat berasal dari industri elektronika, penggunaan fungisida dan insektisida yang berlebihan. Jumlah logam tembaga yang diperbolehkan terakumulasi dalam air adalah 1,3 ppm dan bila lebih akan bersifat toksik dan dapat menyebabkan gangguan tertentu pada mahluk hidup, sehingga diperlukan langkah-langkah pencegahan berupa pengambilan atau pemisahan logam berat tembaga tersebut.

Salah satu cara pengambilan logam tembaga pada limbah cair dengan metode elektrolisis telah dilakukan oleh Nurindah (2004) meberikan hasil yang kurang memuaskan dan memiliki keterbatasan tentang tingginya beaya operasional. Metode elektrolisis internal dapat diterapkan untuk memisahkan dan mengambil tembaga dari larutannya dengan arus yang dihasilkannya sendiri, sehingga perlu upaya untuk memperoleh kondisi optimal dalam peningkatan efisiensi pengendapan.

Elektrolisis internal adalah metode elektrolisis yang memungkinkan untuk melakukan elektrolisis tanpa menggunakan potensial dari luar, dengan katoda dan anoda tercelup dalam larutan elektrolit yang sama atau nasing-masing elektroda tercelup pada larutan elektrolit yang terpisah dengan dihubungkan oleh jembatan garam. Sistem yang diperoleh adalah sel galvani dengan logam $\mathrm{Zn}$ sebagai anoda akan mentrasfer elektron dan masuk ke dalam larutan dalam bentuk ion-ion $\mathrm{Zn}^{2+}$. Elektron yang dihasilkan bergerak melalui kawat tembaga menuju elektroda platina dan ditransfer ke ion-ion $\mathrm{Cu}^{2+}$ dan mengendap dikatoda. Reaksi spontan dapat terjadi apabila perubahan energi bebas reaksinya 
adalah lebih kecil dari nol $\left(\Delta \mathrm{G}_{\text {reaksi }}<0\right)$, reaksi yang terjadi dalam elektrolisis internal adalah $\mathrm{Cu}^{2+}+\mathrm{Zn} \rightarrow \mathrm{Cu}+\mathrm{Zn}^{2+}$

Menurut Nernst besarnya potensial sel adalah

$$
E_{s e l}=E_{s e l}^{0}-\frac{0,059}{2} \log \left(\frac{a_{C u .} \cdot a_{Z n^{2+}}}{a_{C u^{2+}} \cdot a_{Z n}}\right)
$$

Besarnya $E_{\text {sel }}$ dipengaruhi oleh aktivitas dari ion $\mathrm{Zn}^{2+}$ dan ion $\mathrm{Cu}^{2+}$. Pada keadaan standar $E_{\text {sel }}=E_{\text {sel }}^{0}=E_{\mathrm{Cu}^{2+} / \mathrm{Cu}}^{0}-E_{\mathrm{Zn}^{2+} / \mathrm{Zn}}^{0}=1,1$ volt yang berarti dapat berlangsung secara spontan tanpa mensuplai potensial dari luar. Pada elektrolisis internal pengendapan secara sempurna diperlukan waktu yang lama tetapi tidak memerlukan perhatian yang serius selama proses berlangsung. Terjadinya polarisasi pada sel galvani akan memberikan potensial yang lebih rendah terhadap potensial yang diramalkan sebelumnya.Faktor lain yang sangat mempengaruhi metoda elektrolisis internal adalah adanya contact precipitation pada anoda, hal ini dapat diatasi dengan melapisis anoda yang digunakan dengan membran. Dalam penelitian ini dipelajari pengaruh waktu elektrolisis, jarak antar elektroda dan penggunaan membran pada elektrolisis internal terhadap peningkatan efisiensi pengendapan $\mathrm{Cu}$ pada katoda dari limbah cair. Kelanjutan hasil penelitian ini dapat difungsikan pada perancangan metoda elektrolisis internal pada industri yang banyak membuang limbah logam berat yang tidak jarang terdapat dengan kadar yang cukup tinggi dapat menyebabkan pencemaran lingkungan, padahal sangat potensial untuk ditambang kembali.

\section{METODA PENELITIAN}

Bahan yang digunakan: $\mathrm{CuSO}_{4} .5 \mathrm{H}_{2} \mathrm{O}$ p.a, $\mathrm{HNO}_{3}$ p.a, aseton, membran agar, $\mathrm{HCl}$ p.a

Alat yang gunakan: set elektrolisis, plat platina, plat seng, hot plate multimeter, neraca analitik, AAS dan alat gelas.

\section{Preparasi reagen}

Pembuatan larutan $\mathrm{CuSO}_{4}$ 0,05 M: kristal $\mathrm{CuSO}_{4}$ $5 \mathrm{H}_{2} \mathrm{O}$ ditimbang seberat 12,475 gram dilarutkan dalam $100 \mathrm{~mL}$, kemudian ditambahkan akuades sampai batas.

Pembuatan limbah tiruan: lembar PCB ukuran 5x $5 \mathrm{~cm}$ dilarutkan dalam $100 \mathrm{~mL} \mathrm{FeCl}_{3}$ dalam labu ukur $500 \mathrm{~mL}$, ditambahkan akuades sampai batas.

\section{Desain alat}

Katoda plat platina ukuran 3,5x $2 \mathrm{~cm}$ dihubungkan dengan anoda plat seng 3,5 x $1 \mathrm{~cm}$ dengan kabel tembaga. Katoda dan anoda dicelupkan dalam larutan kemudian dihubungkan dengan multimeter.

\section{Percobaan}

Larutan $\mathrm{CuSO}_{4}$ sebanyak $50 \mathrm{ml}$ dipanaskan sampai suhu $60-65^{\circ} \mathrm{C}$ permukaan katoda dan anoda dibersihkan, keduanya disambungkan, kemudian dimasukan dalam larutan. Suhu larutan dijaga tetap, dan di biarkan elektroda di dalam larutan.Elektrolisis di lakukan dengan variasi waktu 30; 60; 90; 120; 200; 270 dan 300 menit dan variasi jarak antara elektroda $1 ; 2 ; 2,5$; 3 dan 3,5 cm. Elektrolisis internal menggunakan membran agar pada limbah tiruan dilakukan selama 300 menit dan jarak antara elektroda $1 \mathrm{~cm}$ Kuantitas tembaga yang mengendap pada katoda dianalisis dengan AAS.

\section{HASIL DAN PEMBAHASAN}

Pada proses elektrolisis dengan elektrolit $\mathrm{CuSO}_{4}$ anoda seng akan teroksidasi dan kation $\mathrm{Cu}^{2+}$ dari elektrolit akan tereduksi dan mengendap pada katoda. Pemanasan pada temperatur $60-65^{\circ} \mathrm{C}$ dimaksudkan untuk mempercepat migrasi elektron dari anoda menuju katoda. Harga potensial sel awal yang timbul adalah $+1,0$ volt dan mengalami penurunan arus selama elektrolisis berlangsung sejalan dengan menurunnya konsentrasi elektrolit dalam larutan. 


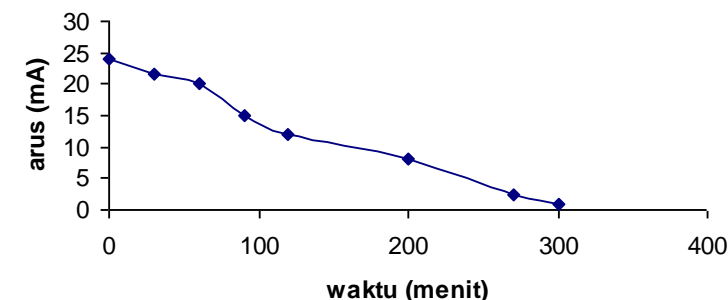

Gambar 1. Pertautan waktu elektrolisis terhadap penurunan arus

Terjadinya polarisasi pada sel elektrolisis internal ini memberikan potensial yang lebih rendah bila dibandingkan dengan potensial yang diramalkan sebelumnya yang disebabkan komposisi elektrolit dan temperatur larutan.

Pengaruh waktu elektrolisis terhadap massa hasil endapan dan perhitungan efisiensi pengendapan disajikan pada tabel berikut ini

Tabel 1. Efisiensi pengendapan elektrolisis pada variasi waktu

\begin{tabular}{cccc}
\hline $\begin{array}{c}\text { Waktu } \\
\text { (menit) }\end{array}$ & $\mathrm{M}_{1}(\mathrm{mg})$ & $\mathrm{M}_{2}(\mathrm{mg})$ & $\begin{array}{c}\text { Efisiensi } \\
(\%)\end{array}$ \\
\hline 30 & 7,73 & 16,14 & 47,88 \\
60 & 8,58 & 27,41 & 31,30 \\
90 & 15,08 & 35,27 & 42,76 \\
120 & 16,03 & 40,75 & 39,34 \\
200 & 18,02 & 47,76 & 37,85 \\
270 & 18,69 & 51,31 & 36,42 \\
300 & 19,24 & 51,94 & 37,04 \\
\hline
\end{tabular}

Keterangan

$\mathrm{M}_{1}$ : massa tembaga yang mengendap secara praktek

$\mathrm{M}_{2}$ : massa tembaga yang mengendap secara teori

Dari hasil tersebut terlihat bahwa semakin lama waktu elektrolisis maka semakin menurun efisiensi pengendapan karena hambatan elektrolit semakin meningkat, dan arus yang digunakan semakin kecil.

Elektrolisis dilakukan pada variasi jarak antar elektroda $1 \mathrm{~cm}$ sampai $3,5 \mathrm{~cm}$. Grafik pertautan arus yang terjadi dengan jarak antar elektroda ditunjukkan pada gambar 2.

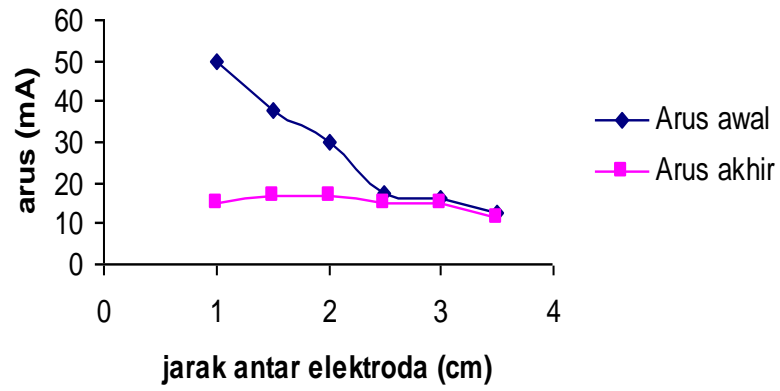

Gambar 2. Pengaruh jarak antar elektroda terhadap arus elektrolisis

Dari gambar 2 dapat dijelaskan bahwa semakin panjang jarak elektroda maka semakin kecil arus yang digunakan, mengakibatkan mobilitas ion di dalam larutan kecil sehingga tidak cukup untuk mengangkut reaktan menuju atau dari permukaan elektroda pada laju yang dibutuhkan oleh arus secara kontinyu, akibatnya endapan yang terbentuk semakin sedikit.

Kelemahan utama dari metoda elektrolisis internal dikenal dengan contact precipitation yaitu penempelan logam pada anoda karena adanya oksidasi yang semakin lama akan terbentuk endapan yang menutupi plat seng sehingga menghambat proses transfer elektron, maka untuk mencegah hal tersebut anoda dilapisi dengan membran. Membran yang digunakan adalah membran agar. Dari penelitian diperoleh hasil bahwa massa tembaga yang mngendap tanpa menggunakan membran lebih besar yaitu 18,69 $\mathrm{mg}$ dari pada dengan menggunakan membran sebesar 14,67 mg. Hasil penelitian menunjukkan bahwa dengan menggunakan membran, jumlah tenbaga yang mengendap lebih sedikit disebabkan oleh dua kemungkinan, yang pertama yaitu membran agar ikut larut dalam larutan elektrolit sehingga anoda tidak cukup terlindungi dari proses oksidasi lebih lanjut. Kedua adanya potensial membran yang menghalangi potensial sel yang disebut liquid junction membrane. Kelemahan lain dari metoda elektrolisis internal adalah waktu yang digunakan relatif lebih lama dibandingkan dengan metoda elektrolisis. 


\section{KESIMPULAN}

Metoda elektrolisis internal dapat digunakan untuk mengedapkan tembaga dalam larutan, dengan meningkatnya waktu maka endapan tembaga yang terbentuk semakin banyak dengan efisiensi pengendapan semakin kecil. Semakin panjang jarak antar elektroda mengakibatkan massa endapan yang terendapkan semakin sedikit. Membran agar tidak mampu meningkatkan tembaga yang mengendap, sehingga perlu dilakukan nasing-masing elektroda tercelup pada larutan elektrolit yang terpisah dengan dihubungkan oleh jembatan garam yang terdispersi dalam agar-agar. Aplikasi elektrolisis internal pada limbah tiruan hanya mampu menurunkan kadar tembaga dari konsentrasi 179,7 ppm menjadi 5,6 ppm sedangkan logam tembaga yang diperbolehkan terakumulasi dalam air adalah 1,3 ppm.

\section{UCAPAN TERIMAKASIH}

Ucapan terimakasih kami sampaikan kepada kepala Laboratorium Kimia Analitik Universitas Diponegoro yang telah memberikan sarana dalam penelitian ini, juga kami sampaikna kepada Bp. Didik S Widodo atas saran dan koreksi yang telah diberikan.

\section{DAFTAR PUSTAKA}

Crow, D.R., 1998, Principles and Application of Electrochemistry, Chapman and Hall Inc.: London, pp: 200-202

Douglas, M., Considine, P.E., 1984, Encyclopedia of Chemistry, $4^{\text {th }}$ ed. New York: Van Nonstrand Reinhold Company, pp.: 287-292

Imam Khasani, S., dkk. 1995., Cara Memperoleh Kembali Tembaga dan Amonia dari Limbah Industri Pembuat PCB, Buletin IPT, pp.: 25-28.

Kirk, R.E., Othmer, D.F., 1983, Encyclopedia of Chemical Technology, vol.8; The Interscience Encyclopedia Inc.: New York; p.p: $147-176$

Reger, Weiner, Gilkerson, 1993, Experimentation and Analysis in Chemistry Laboratory, Sounder College, pp.: 371-378
Skoog, D.A., West, D.M., 1971, Principles of Instrumental Analysis, Philadelphia: Stanford University Sounders College Publishing, pp.:532-534. 